unclear, although it is generally considered a result of increased blood flow to the lungs or weakening of the vessel wall. When associated with pulmonary sequestration and agenesis, BAA is considered congenital. It also may be acquired, arising in response to inflammatory lung disease, bronchiectasis, atherosclerosis, tuberculosis, or trauma. A systemic vascular abnormality has been described in BAA, such as Osler-Weber-Rendu disease. The location of the BAA is classified as either mediastinal or intrapulmonary. Mediastinal BAAs have multiple symptoms, including compression or rupture into contiguous anatomic structures (the esophagus, trachea, bronchus, superior vena cava, and heart). In contrast, hemoptysis is the most common symptom of intrapulmonary BAA. ${ }^{3,4}$

Kalangos and colleagues ${ }^{3}$ summarized 15 cases of reported BAA. Mean size of the BAAs in their series was $12.8 \mathrm{~mm}(5-30 \mathrm{~mm})$. Our case demonstrates that even a small BAA $(7 \mathrm{~mm})$ can have a life-threatening rupture. BAA thus should be treated regardless of size or symptoms. Two treatment approaches have been used for BAA. One is an interventional approach with transcatheter bronchial artery embolization. This has been increasingly used to treat BAA because it is less invasive. Aorta stent-graft placement is also a good technique for the treatment of BAA. The other is a surgical approach with ligation or resection for the removal of lesions. The surgical approach is especially effective for a ruptured BAA. In cases with massive bleeding, cardiopulmonary bypass is helpful to treat uncontrollable bleeding. ${ }^{2-5}$

In our case, the BAA was ruptured, and massive bleeding occurred in the mediastinum. A huge hematoma was compressed to the left atrium, causing the unstable vital signs. Before surgery, we performed selective bronchial artery angiography to identify the ruptured part accurately and thus prevent uncontrollable bleeding during the surgery. After successful transcatheter bronchial artery embolization, the hematoma was surgically removed.

\section{References}

1. Fujita J, Akashi K, Kunikane H, Nakajima I, Saito S, Abe S, et al. [A case of bronchial artery aneurysm demonstrating a mass shadow on chest X-ray film]. Nihon Kyobu Shikkan Gakkai Zasshi. 1991;29:1591-5. Japanese.

2. Hu CX, Huang S, Xu ZW, Chen W, Huang JS, Fu Z. Combination of aortic stent-graft and arterial embolization for ruptured bronchial artery aneurysm. Ann Thorac Surg. 2011;92:e19-21.

3. Kalangos A, Khatchatourian G, Panos A, Faidutti B. Ruptured mediastinal bronchial artery aneurysm: a dilemma of diagnosis and therapeutic approach. J Thorac Cardiovasc Surg. 1997;114:853-6.

4. Tanaka K, Ihaya A, Horiuci T, Morioka K, Kimura T, Uesaka T, et al Giant mediastinal bronchial artery aneurysm mimicking benign esophageal tumor: a case report and review of 26 cases from literature. J Vasc Surg. 2003; $38: 1125-9$.

5. Sanchez E, Alados P, Zurera L, Canis M, Munoz I, Casares J, et al. Bronchial artery aneurysm treated with aortic stent graft and fibrin sealant. Ann Thorac Surg. 2007;83:693-5.

\title{
From relapsing polychondritis to extracorporeal membrane oxygenation
}

\author{
Delphine Mitilian, MD, ${ }^{\mathrm{a}}$ François Gonin, MD, ${ }^{\mathrm{a}}$ Edouard Sage, MD, ${ }^{\mathrm{a}}$ and Sylvain Beurtheret, MD, \\ Suresnes and Marseille, France
}

Relapsing polychondritis (RP) is a multisystem inflammatory disease of unknown etiology affecting mainly chondritis of auricular, nasal and tracheal cartilage. Recurrent episodes of inflammation result in cartilage destruction and malacia of the airways. It often requires challenging

\footnotetext{
From the Department of Thoracic Surgery and Lung Transplantation, ${ }^{\mathrm{a}}$ Foch Hospital, Université de Médecine Paris-Île-de-France-Ouest, Suresnes, France; and the Department of Cardiac Surgery, ${ }^{\text {b }}$ Saint Joseph Hospital, Marseille, France. Disclosures: Authors have nothing to disclose with regard to commercial support. Received for publication March 7, 2013; revisions received June 16, 2013; accepted for publication July 3, 2013; available ahead of print Aug 30, 2013.

Address for reprints: Delphine Mitilian, MD, Department of Thoracic Surgery, Hôpital Foch, 40 rue Worth 92150 Suresnes, France (E-mail: dmitilian@gmail. com).

J Thorac Cardiovasc Surg 2013;146:e49-51

$0022-5223 / \$ 36.00$

Copyright (C) 2013 by The American Association for Thoracic Surgery

http://dx.doi.org/10.1016/j.jtcvs.2013.07.016
}

endoscopic stent placement. We report the case of an extended tracheal and bronchial membranous laceration treated conservatively, with a total weaning from mechanical ventilation thanks to venovenous extracorporeal membrane oxygenation (ECMO).

\section{CLINICAL SUMMARY}

A 41-year-old man with a diagnosis of RP underwent an elective tracheobronchial endoscopy. Because of the global airway malacia, Y-prosthesis placement was attempted. The procedure was complicated by bronchial edema and perforation of the tracheal membranous wall extending from the carina to the main bronchi, leading to bilateral tension pneumothorax and hemodynamic instability. The situation was initially stabilized by insertion of a single tracheal prosthesis, allowing safe intubation and by 

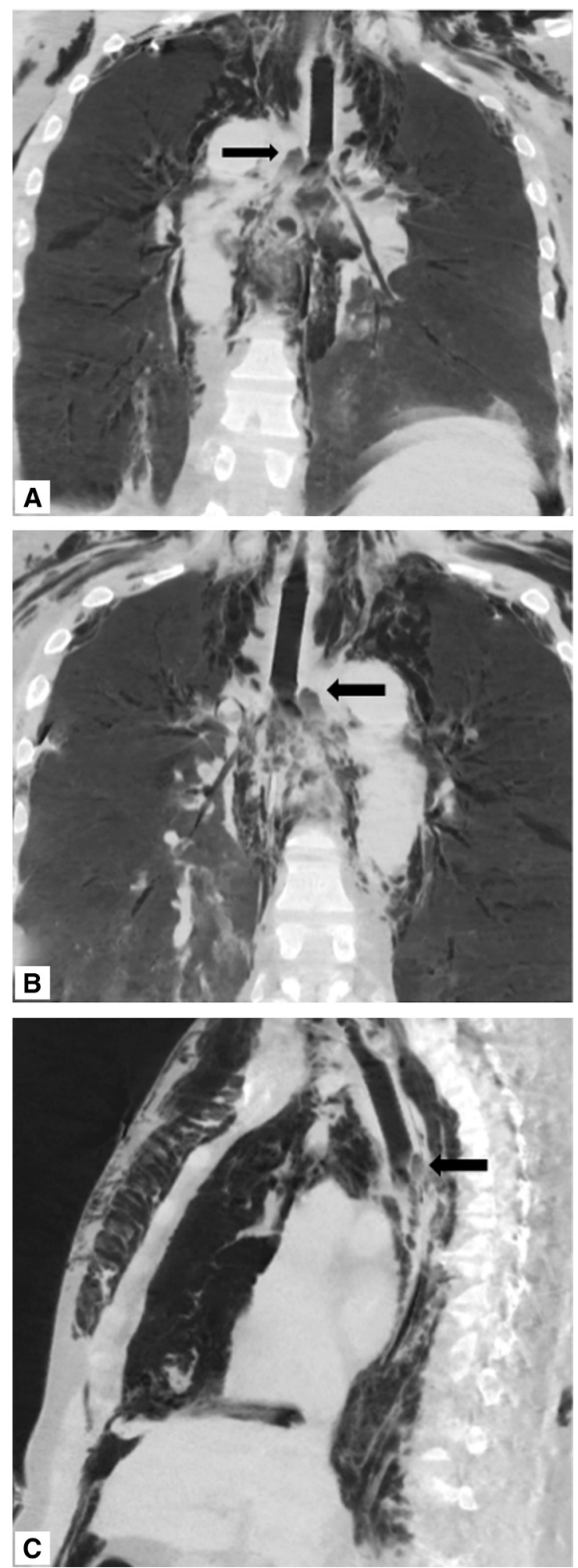

FIGURE 1. Computed tomographic reconstructions. A, The black arrow points to the right main bronchial fistula zone, showing abnormal air presence. B, The black arrow points to the left main bronchial fistula. C, Sagittal view showing subcutaneous emphysema and pneumomediastinum. The black arrow points at the carinal fistula zone.
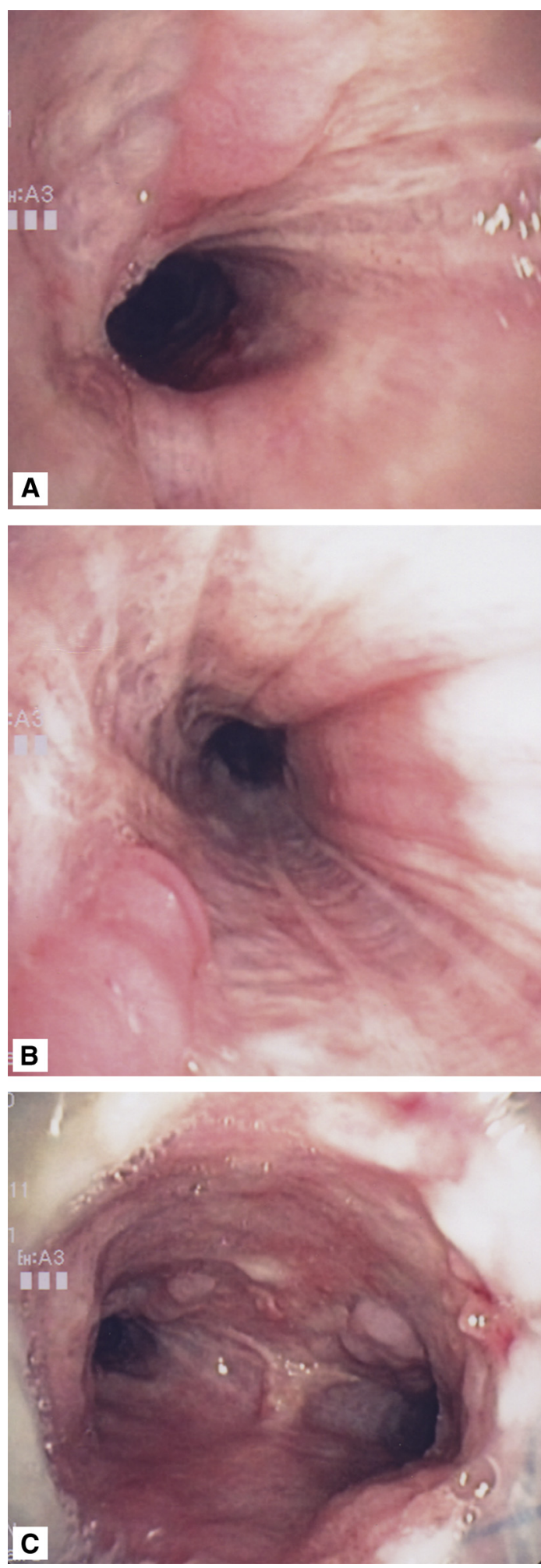

FIGURE 2. Most recent endoscopic views after total healing. A, Left main bronchus. B, Right main bronchus. C, Carina, fully healed with several nonobstructive granulomas. 
bilateral pleural drain insertion. No other prosthesis could be safely and durably reinserted because of the severe membranous perforation. The patient was transferred to the intensive care unit. Hemodynamic status was stabilized; however, the respiratory management remained challenging. Inflammatory edema and malacia required high ventilation pressures but resulted in massive air leakage and compromised airway healing. At day 3, endoscopy confirmed important worsening of the lesions under mechanical ventilation. After a failed extubation attempt, we performed a tracheotomy to promote a faster respiratory weaning. On day 6 , mechanical ventilation was still required and a pneumonediastinum and pneumoperitoneum occurred, causing gas tamponade and higher ventilation difficulties (Figure 1). After urgent percutaneous drainage of the mediastinum, the decision was made to implant percutaneously a venovenous ECMO from the right femoral vein to the right jugular vein, to correct hypoxemia and hypercapnia (pH 7.19; $\mathrm{Po}_{2}, 64 \mathrm{~mm} \mathrm{Hg} ; \mathrm{PCO}_{2}, 110 \mathrm{~mm} \mathrm{Hg}$ ). Flow rates were adapted to the patient cardiac output (5.6 $\mathrm{L} / \mathrm{min}, 4000 \mathrm{rpm}$ ) and to obtain an oxygen saturation greater than $90 \%$. Prophylactic anticoagulation therapy was decided.

Blood gas values were optimized ( $\mathrm{pH} 7.46 ; \mathrm{Po}_{2}, 84 \mathrm{~mm}$ $\mathrm{Hg} ; \mathrm{PCO}_{2}, 51 \mathrm{~mm} \mathrm{Hg}$ ). Sedation was stopped, and the patient recovered spontaneous ventilation with complete mechanical ventilation weaning within hours. Air leakage decreased, as did subcutaneous emphysema, pneumomediastinum, and pneumoperitoneum, and stopped completely at day 15 . Healing was checked by regular endoscopies. After 1 week of ECMO, hemostasis troubles characterized by bleeding around cannulas required blood transfusions.

ECMO was removed after 14 days, when complete healing was obtained, with normal blood gas values. Cannulation of the tracheotomy was discontinued. Hospital discharge was possible after 36 days. The most recent endoscopy control on day 45 confirmed correct healing of the airways without any obstruction (Figure 2).

\section{DISCUSSION}

Pulmonary manifestations of RP are characterized by tracheobronchomalacia, which may need iterative endoscopic stent placement. ${ }^{1}$ These inflammatory tissues are fragile, and therapeutic endoscopy may lead to severe or even lethal complications. $^{2}$ This case of life-threatening bilateral tension pneumothorax and pneumomediastinum occurred after a bronchial tear during Y-prosthesis insertion in a patient with RP and bilateral main bronchial obstruction.

In usual traumatic airway injuries, spontaneous ventilation is the best way to heal. If mechanical ventilation is required, several conservative solutions have been described to avoid ventilation's harmful effects, such as selective intubation, balloon placement, and prosthesis insertion. ${ }^{3}$ None of these solutions was suitable for our patient because of the size, the location of the lesions, and the fragility of the inflammatory tissues. Surgery would have been extensive, probably worsening the lesions and inflammation.

Venovenous ECMO is now commonly used in various adult respiratory distress syndrome situations to allow improvement of oxygenation and protective ventilation, avoiding mechanical ventilation-related damage. ${ }^{4}$ It has seldom been described in association with the surgical treatment of tracheobronchial disruption. ${ }^{5}$ Awake ECMO initiation has already been performed for different clinical features; however, no case of tracheobronchial tear treated exclusively with venovenous ECMO, permitting total spontaneous healing, has been reported previously.

Complications of ECMO are now well known and often avoidable. Benefits and risks of this technique should be discussed for each clinical situation. In our case, venovenous ECMO was the most reliable, conservative, and efficient therapy to treat this tracheobronchial laceration.

This report emphasizes an unexpected advantage of ECMO. Whereas it was initially implanted to fix a lifethreatening situation where mechanical ventilation was dangerous and inefficient, ECMO allowed, above all, awake spontaneous ventilation. Avoiding mechanical ventilation's barotraumatic effect, it broke the vicious circle of mechanical ventilation, which was both necessary for survival but deleterious to the healing process. It thus became the most effective way to allow spontaneous healing of these tracheobronchial lesions. ECMO initiation could be discussed earlier in cases of airway injuries in which mechanical ventilation remains an impasse.

\section{References}

1. Sarodia BD, Dasgupta A, Mehta AC. Management of airway manifestations of relapsing polychondritis: case reports and review of literature. Chest. 1999;116: 1669-75.

2. Lin YT, Zuo Z, Lo PH, Hseu SS, Chang WK, Chan KH, et al. Bilateral tension pneumothorax and tension pneumoperitoneum secondary to tracheal tear in a patient with relapsing polychondritis. J Chin Med Assoc. 2009;72: 488-91.

3. Beiderlinden M, Adamzik M, Peters J. Conservative treatment of tracheal injuries. J Anesth Analg. 2005;100:210-4.

4. Iglesias M, Jungebluth P, Petit C, Matute MP, Rovira I, Martinez E, et al Extracorporeal lung membrane provides better lung protection than conventional treatment for severe postpneumonectomy noncardiogenic acute respiratory distress syndrome. J Thorac Cardiovasc Surg. 2008;135:1362-71.

5. Raake J, Johnson B, Seger B, Manning PB, Eghtesady P, Boesch P, et al. Extracorporeal membrane oxygenation, extubation, and lung-recruitment maneuvers as rescue therapy in a patient with tracheal dehiscence following slide tracheoplasty. Respir Care. 2011;56:1198-202. 